\title{
Ces personnes qu'on idéalise
}

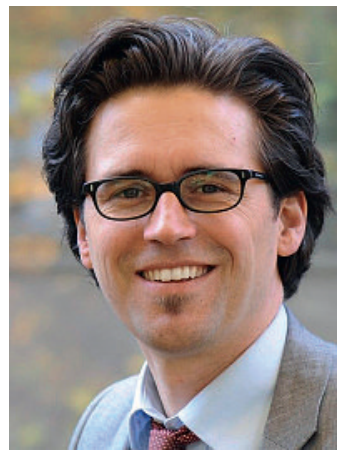

Rouven Porz
* Dr phil., biol. dipl., Rouven Porz est responsable du service Ethique de l'Hôpital de l'Ile à Berne, chercheur à l'Institut für Biomedizinische Ethik de Zurich, secrétaire général de la European Association of Centres of Medical Ethics (EACME) et membre de la rédaction Ethique du BMS.
J'ai récemment été en contact par courriel avec une professeure de philosophie tout à fait brillante. Nos échanges portaient sur l'écrivain français Albert Camus, et cette remarquable professeure a terminé son courriel par à peu près ces mots: «Ah vous savez, Monsieur Porz, il nous manque aujourd'hui des modèles comme Camus.» Depuis, impossible de me sortir cette phrase de la tête. Je crois qu'elle a raison. Il y a actuellement un nombre impressionnant d'experts, mais quasiment plus de modèles. Cela me semble être particulièrement vrai dans notre système de santé. Les experts peuvent être facilement remplacés, pas les modèles.

Et vous, avez-vous actuellement un modèle? Ou alors en aviez-vous lorsque vous étiez plus jeunes? Je sais qu'on ne parle pas volontiers de ses propres modèles. Ils touchent à quelque chose de personnel, d'intime. Ils dévoilent quelque chose sur le genre de personnes que l'on a autrefois admiré, ou que l'on aurait peut-être aimé devenir.

Allez, je me lance. Petit garçon, mon modèle sportif était un milieu de terrain très connu du Borussia Mönchengladbach (qui

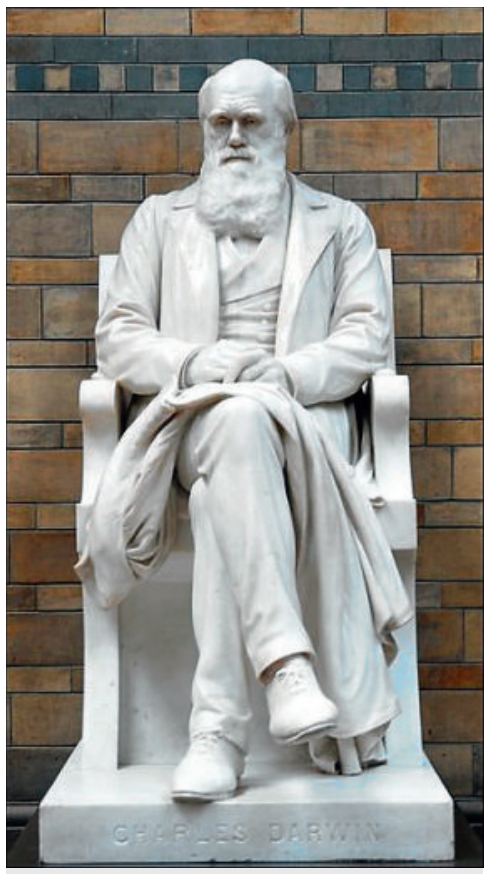

Charles Darwin: un modèle de courage. Car il en fallait du courage pour nous dire, à nous les humains, que nous descendons d'ancêtres simiesques. lui-même comme une sorte de modèle. A ce momentlà, une page s'est tournée pour moi et, malheureusement, il venait de perdre un adepte. Les modèles ne peuvent pas se déclarer eux-mêmes modèles de quelqu'un. Ce serait un comble.

Quelques années plus tard, je me suis intéressé de près à la biologie et particulièrement à la théorie de l'évolution, qui me fascinait plus que tout. Les théories ne peuvent pas jouer le rôle de modèle mais leurs fondateurs, si. Je me suis alors penché sur les travaux de Charles Darwin. Darwin est pour moi un modèle de courage. Car il en fallait du courage pour faire admettre, dans notre monde si vaniteux, l'idée selon laquelle nous, les humains, descendons d'ancêtres simiesques.

Et voilà que j'en reviens à Albert Camus. Cet écrivain français, d'origine algérienne, constitue pour moi, avec ses essais, ses œuvres philosophiques et politiques, un véritable modèle moral. Je l'admets, peut-être que j'idéalise Camus, que je le confonds avec ses œuvres, ou que je me fais des idées sur sa vie. Mais heureusement, c'est sans importance; car les modèles n'agissent pas sur le plan de la est plus tard passé au Bayern Munich et a joué un nombre incalculable de matchs avec l'équipe nationale allemande). Il s'est entre-temps fait connaître de la presse à sensation pour sa vie privée quelque peu débridée: tous les deux ans, à peu près, il épouse une femme plus jeune que lui, dont il finit par divorcer. Naturellement, ces frasques personnelles n'ont rien à voir avec sa prestation sportive d'autrefois. Mais ces articles de presse ne me laissent pas indifférent, au contraire, ils m'attristent profondément: c'était quand même mon grand modèle. Cet exemple illustre parfaitement que les modèles peuvent perdre leur rôle d'exemple. Et c'est vraiment dommage.

Pendant la puberté, j'étais un fervent fan d'un groupe irlandais de pop rock. Le chanteur charismatique était un véritable modèle pour moi. Quelques années plus tard, ce chanteur a commencé à user de son charisme sur le plan politique, en se présentant raison, ils agissent sur le plan de l'émotion, de l'imagination et de la psychologie. Les modèles se comportent comme les mythes: on adopte un modèle comme

\section{Les experts peuvent être facile- ment remplacés, pas les modèles.}

on adopte une croyance. Le modèle est un paradigme positif.

Et vous, chers médecins? Etes-vous de simples experts médicaux ou plutôt des modèles pour notre système de santé? Les deux j'espère, car la relève médicale a besoin de visions.

Rouven Porz* 